\title{
Clinicopathological Features of Serrated Adenocarcinoma Defined by Mäkinen in Dukes' B Colorectal Carcinoma
}

\author{
Yosuke Shida $^{a}$ Takahiro Fujimori $^{\mathrm{b}}$ Hiroyuki Tanaka ${ }^{\mathrm{b}}$ Yukari Fujimori ${ }^{\mathrm{b}}$ \\ Ryusuke Kimura $^{\mathrm{b}}$ Hirofumi Ueda ${ }^{\mathrm{b}}$ Kazuhito Ichikawa ${ }^{\mathrm{b}}$ Shigeki Tomita ${ }^{\mathrm{b}}$ \\ Hitoshi Nagata ${ }^{c}$ Keiichi Kubotac Masahiro Tsubaki ${ }^{a}$ Hiroyuki Kato ${ }^{a}$ \\ Takashi Yao $^{d}$ Tamotsu Sugai $^{f}$ Kenichi Sugihara ${ }^{\mathrm{e}}$ Yasuo Ohkurag Johji Imurab \\ Departments of a Surgery 1, b Surgical and Molecular Pathology and ' Surgery 2, Dokkyo University School of \\ Medicine, Mibu, d Department of Human Pathology, Juntendo University School of Medicine and e Department of \\ Surgical Oncology, Graduate School, Tokyo Medical and Dental University, Tokyo, ${ }^{\mathrm{f}}$ Division of Molecular Diagnostic \\ Pathology, Department of Pathology, School of Medicine, Iwate Medical University, Morioka, and ${ }^{9}$ Department of \\ Pathology, Kyorin University School of Medicine, Mitaka, Japan
}

\section{Key Words}

Serrated adenocarcinoma • Serrated neoplasia pathway • Dukes' B

\section{Abstract \\ Objective: Serrated adenocarcinoma (SAC), proposed as a new pathologic type, arises predominantly in the right side of the colon and has a poorer prognosis than conventional colorectal carcinoma. The prognosis of colorectal carcinoma is variable in Dukes' $B$, so the aim of this study was to deter- mine whether or not SAC has a poor prognosis in Dukes' B. Methods: The study group comprised 64 patients who un- derwent surgery for colorectal carcinoma. We undertook a statistical analysis of the association of SAC and non-SAC with sex, age, histologic type, depth of tumor, location of tumor, venous invasion and lymphatic invasion. Results: SACs were encountered in $17.5 \%$ of cases $(n=11)$. SAC had a less favorable 5 -year survival than non-SAC ( $p=0.0396$ log- rank, Kaplan-Meier). The factors that achieved statistical sig-}

nificance in the univariate analysis were subsequently included in a multivariate analysis and we found that SAC was an independent factor $(p=0.027)$. Conclusions: SAC has a poor prognosis and is not affected by other factors confirming that SAC is an independently less favorable prognostic factor.

Copyright $\odot 2012$ S. Karger AG, Basel

\section{Introduction}

Colorectal carcinoma is one of the most common malignancies in the world. The prevalence of colorectal cancer in Japan is second only to stomach cancer in males and breast cancer in females, meaning it has a high prevalence among cancers and this has increased remarkably in recent years [1]. Furthermore, an increasing frequency of deeply invasive colorectal carcinoma (T2-T4 in the TNM classification) has been noted in older Japanese patients, similar to the trend in western patients [2-5]. T1

\section{KARGER}

Fax +41613061234

E-Mail karger@karger.ch

www.karger.com (c) 2012 S. Karger AG, Basel

$1015-2008 / 12 / 0794-0169 \$ 38.00 / 0$

Accessible online at:

www.karger.com/pat
Takahiro Fujimori, MD, PhD

Department of Surgical and Molecular Pathology

Dokkyo University School of Medicine, 880 Kitakobayasi, Mibu, Shimotsuga

Tochigi 321-0293 (Japan)

Tel. +81 28287 2130, E-Mail t-fuji@ dokkyomed.ac.jp 
Table 1. Definition of criteria used in the evaluation of SAC by Mäkinen [17]

\begin{tabular}{ll}
\hline 1 & Epithelial serrations \\
2 & Clear or eosinophilic cytoplasm \\
3 & Abundant cytoplasm \\
4 & Vesicular nuclei \\
5 & Discernible nuclei \\
6 & Absence of necrosis \\
7 & Mucin production \\
8 & Cell balls and papillary rods \\
\hline
\end{tabular}

stage colorectal cancer is located mainly in the sigmoid colon and may be treated by endoscopy, whereas T2-T4 colorectal cancer, which is also found predominantly in the sigmoid colon, must be resected surgically. Of note, the interval cancer has been detected not only in the sigmoid colon but also in the right side of the colon $[6,7]$. These lesions are difficult to detect and possibly may be missed at conventional colonoscopy. There is a serrated lesion at an early stage in the right side of the colon. The serrated neoplasia pathway is currently proposed as the new neoplasia pathway which differs from the adenomacarcinoma sequence [8-12]. Serrated adenocarcinoma (SAC) is considered to be one of several end points of this pathway $[13,14]$ and was discussed first as colorectal carcinoma with similarities to hyperplastic polyps by Jass and Smith [15] in 1992. The morphologic features of SAC were clarified by Tuppurainen et al. [16] in 2005 and manifested by Mäkinen [17] in 2007. Following this, 85 SACs were compared with 823 conventional colorectal carcinomas by García-Solano et al. [13] in 2010, and these authors reported that many SACs were located in the right side of the colon and had a less favorable 5-year survival than conventional colorectal carcinomas.

The prognosis of colorectal carcinoma is variable in Dukes' B, so we determined whether or not SAC is a poor prognostic factor in the first known Japanese trial of its type.

\section{Materials and Methods}

\section{Study Cases and Tissue Samples}

A total of 702 consecutive surgical specimens of colorectal carcinoma (Department of Pathology at the Dokkyo University School of Medicine), excluding postoperative death within 30 days and double cancer cases, were collected from January 2000 to December 2006. Sixty-four cases out of 702 were Dukes' B during more than 5 years of the course of a patient's illness. All of the operations were celiotomies. The surgical procedures of colon cancer were limited colectomy and of the rectum were anterior resection. We evaluated the 64 cases in this study. The locations of the colorectal carcinomas were categorized into three regions: the right side of the colon (cecum, ascending and transverse colon), the left side of the colon (descending and sigmoid colon) and the rectum.

A fresh specimen of the resected intestine was opened along the long axis and placed on a flat board with the mucosal side upwards. Then, the pinned-out intestine was fixed by complete immersion in formalin natural buffer solution for at least $24 \mathrm{~h}$. Several section lines were made along the long axis of the intestine to include the center of the tumor. Block counts of the samples were 4-24 and the average was 8 . We used samples with the greatest depth for HE staining and assessed whether they were SAC or not.

\section{Histologic Evaluation}

The subjects were diagnosed by four pathologists according to the Japanese Classification of Colorectal Carcinoma [5]. Histologic type, depth of tumor, venous invasion and lymphatic invasion were also categorized according to the Japanese Classification of Colorectal Carcinoma [5]. Tumors that contained more than one histologic type of carcinoma were classified based on the predominant histologic type. Well-differentiated tubular adenocarcinoma (tub1) was characterized by distinct and large gland formation; moderately differentiated tubular adenocarcinoma (tub2) was composed of medium to small glands with a cribriform structure, and poorly differentiated adenocarcinoma (Por) had little tendency to form glands or tubules but intracellular mucus production was seen [5]. Depth of tumor invasion was categorized as: invasion to the subserosa or nonperitonealized pericolic or perirectal tissues (SS) [18]; invasion penetrating the serosa (SE), and direct invasion to adjacent organs or structures (SI) [5]. Venous invasion was categorized as either no invasion $(\mathrm{V}-)$ or recognized intramural invasion $(\mathrm{V}+)$. Lymphatic invasion was categorized similarly as either (Ly-) or (Ly+).

\section{Histologic Definition of SAC}

The morphological characteristics of SAC were defined by Mäkinen as invasive growth; however, the pathological general definition of SAC is tubular adenocarcinoma with serration. We selected the subjects with deeply invasive colorectal carcinoma, meaning a diagnosis of SAC was considered when colorectal carcinoma fulfilled all eight items of Mäkinen's histologic criteria of SAC. SAC was diagnosed by four pathologists (T.F., S.T., J.I. and K.I.) and one surgeon (Y.S.) on the basis of the greatest depth of sample with HE staining $[12,16]$. The selected cases were evaluated by intraobservation (T.F., S.T., J.I., K.I. and Y.S.) and interobservation (T.S.). In this study, we examined the full agreement cases in intraobservation and interobservation. The morphological criteria and illustrations for SAC described by Mäkinen [17] are set out in table 1 and figure 1.

\section{Statistical Analysis}

Statistical analysis was performed using the Stat Flex program package (v.6). Mann-Whitney's U test, Fisher's exact test or $\chi^{2}$ test were used for the statistical analysis of the association of SAC and non-SAC with sex, age, histological type, depth of tumor, location of tumor, venous invasion and lymphatic invasion. Kaplan-Meier survival curves were used to calculate 5-year survival statistics 

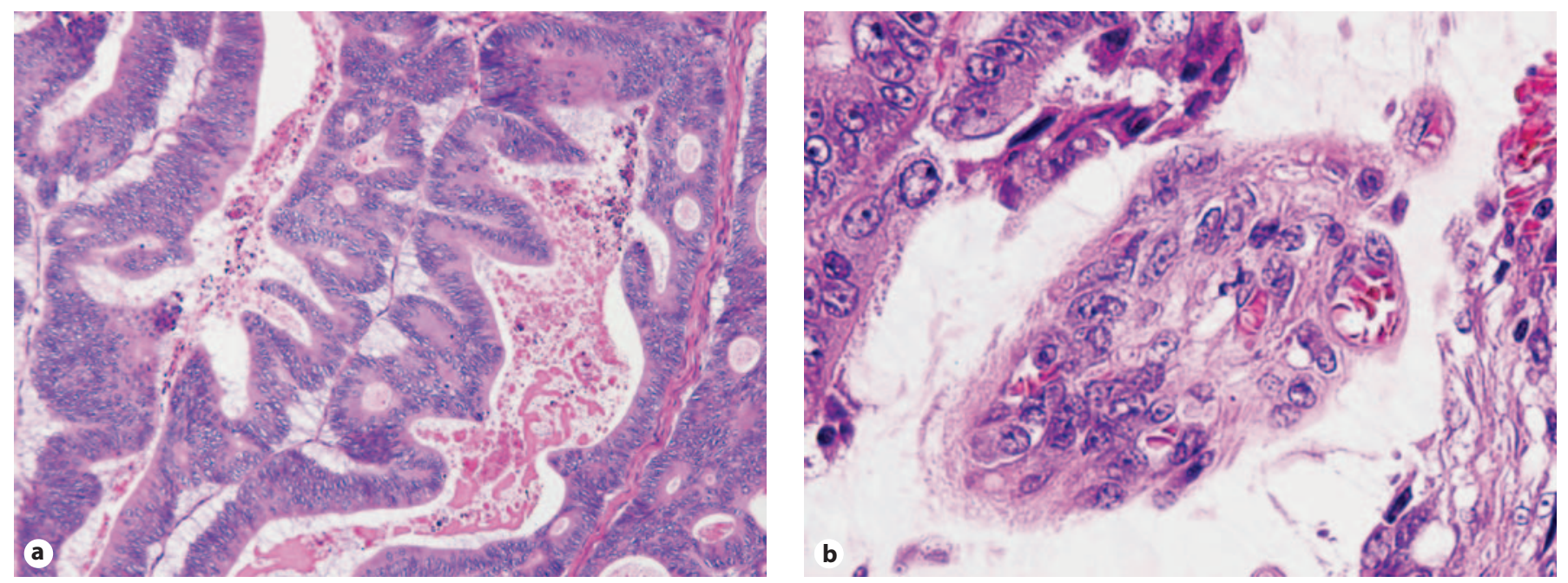

Fig. 1. The morphology of SAC. a SAC showing epithelial serrations, abundant and eosinophilic cytoplasm, and vesicular nuclei. HE. $\times 100$. $\mathbf{b}$ SAC showing cell balls floating in the extracellular mucin. HE. $\times 500$. c SAC showing papillary rods in the extracellular mucin. HE. $\times 400$.

between SAC and non-SAC and differences in survival between the two groups were compared using the log-rank test. Death was considered the end point for survival analysis. We considered the factors (sex, age, histological type, depth of tumor, location or tumor, venous invasion and lymphatic invasion) which affected prognosis and calculated the 5-year survival statistics of the factors using the Kaplan-Meier method. Following this, we classified the factors into binary data. Multivariate analysis was performed using a Cox proportional hazards regression model. Differences were considered to be statistically significant at $\mathrm{p}<0.05$ [19].

\section{Results}

Comparison of the Clinicopathological Characteristics of SAC and Non-SAC

There were 11 SAC (17.2\%) and 53 non-SAC (82.8\%) cases among the total of 64 . There were 8 males and $3 \mathrm{fe}-$

males with SAC and 34 males and 19 females with nonSAC. The most common location of the tumor was the rectum in both SAC and non-SAC. The most common histologic type was tub2 in SAC (72.7\%) and non-SAC (79.2\%), and only 1 case was classified as Por. The depth of tumor was mostly SS in SAC and non-SAC. Venous invasion was classified as $4 \mathrm{~V}$ - and $7 \mathrm{~V}+$ in SAC, and 21 $\mathrm{V}-$ and $33 \mathrm{~V}+$ in non-SAC. Lymphatic invasion was classified as $2 \mathrm{Ly}-$ and $9 \mathrm{Ly}+$ in SAC, and $9 \mathrm{Ly}-$ and $45 \mathrm{Ly}+$ in non-SAC. No statistical differences were found between SACs and non-SACs with respect to the distribution of sex, age, histological type, depth, location, venous invasion and lymphatic invasion (table 2).

\section{Univariate Analysis}

Six cases of SAC and 42 cases of non-SAC were alive more than 60 months after the surgical procedure. Using 
Table 2. Clinical and pathological features of serrated and nonserrated adenocarcinoma

\begin{tabular}{|c|c|c|c|}
\hline & $\begin{array}{l}\text { SAC } \\
(n=11)\end{array}$ & $\begin{array}{l}\text { non-SAC } \\
(\mathrm{n}=53)\end{array}$ & $\mathrm{p}$ value \\
\hline \multicolumn{4}{|l|}{ Sex } \\
\hline Male & 8 & 34 & \\
\hline Female & 3 & 19 & 0.735 \\
\hline Age & $71(64.3,79.3)$ & $67(59.0,75.0)$ & 0.203 \\
\hline \multicolumn{4}{|c|}{ Location of tumor } \\
\hline Right side & 3 & 14 & \\
\hline Left side & 2 & 17 & \\
\hline Rectum & 6 & 22 & 0.622 \\
\hline \multicolumn{4}{|c|}{ Histological type } \\
\hline tub1 & 3 & 10 & \\
\hline tub2 & 8 & 42 & \\
\hline Por & 0 & 1 & 0.751 \\
\hline \multicolumn{4}{|c|}{ Depth of tumor } \\
\hline SS & 10 & 49 & \\
\hline SE & 0 & 4 & \\
\hline SI & 1 & 1 & 0.306 \\
\hline \multicolumn{4}{|c|}{ Venous invasion } \\
\hline $\mathrm{V}-$ & 4 & 21 & \\
\hline $\mathrm{V}+$ & 7 & 33 & 1.000 \\
\hline \multicolumn{4}{|c|}{ Lymphatic invasion } \\
\hline Ly- & 2 & 9 & \\
\hline Ly+ & 9 & 45 & 1.000 \\
\hline
\end{tabular}

Table 3. Univariate analysis of risk factors

\begin{tabular}{ll}
\hline Risk factor & p value \\
\hline Sex (male vs. female) & 0.804 \\
Age ( $\geq 70$ vs. <70) & 0.032 \\
Histological type (well vs. moderate) & 0.967 \\
Depth of tumor (SS vs. SI or SE) & 0.000 \\
Location of tumor: & \\
$\quad$ right side vs. rectum or left side & 0.490 \\
$\quad$ left side vs. right side or rectum & 0.610 \\
$\quad$ rectum vs. right side or left side & 0.275 \\
V+ vs. V- & 0.184 \\
Ly+ vs. Ly- & 0.542 \\
SAC vs. non-SAC & 0.040 \\
\hline
\end{tabular}

the Kaplan-Meier analysis of 5-year follow-up, SACs were associated with a less favorable outcome than non-SACs ( $\mathrm{p}=0.0396$, log-rank test; fig. 2). The univariate analyses of risk factors, including sex, age, location, histological type (tub1 vs. tub2, excluding 1 case of Por), depth, venous invasion, lymphatic invasion and SAC versus non-

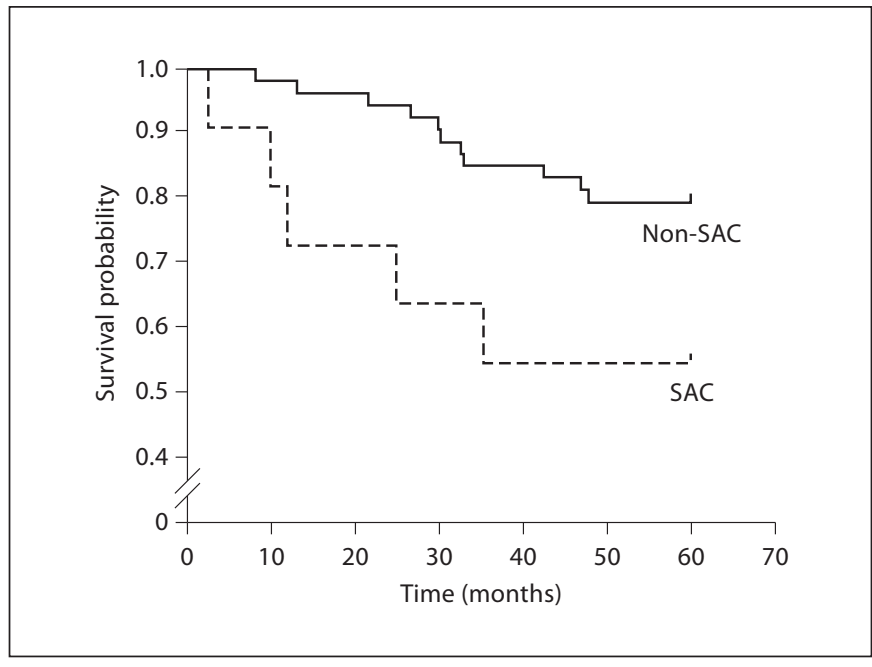

Fig. 2. Survival curves of cumulative incidence death rate of patients with SAC versus non-SAC during 5-year follow-up. $\mathrm{p}=$ 0.0396 (log-rank test), Kaplan-Meier survival curve.

SAC, are summarized in table 3 . There were statistically significant differences between age ( $\geq 70$ vs. $<70$, p $=$ 0.032 ), depth (SS vs. SI or SE, $p=0.000$ ) and SAC versus non-SAC ( $p=0.040)$ as risk factors. We could not analyze the clinicopathological differences of the depth through SE versus SS or SI, and SI versus SS or SE because the numbers of these cases were too small.

\section{Multivariate Analysis}

SAC versus non-SAC, age ( $\geq 70$ vs. $<70)$ and depth (SI or SE vs. SS) factors that achieved statistical significance in the univariate analysis were subsequently included in a multivariate analysis using the Cox proportional hazard regression model. There were no statistically significant differences between over 70 -year-olds and under 70 -year-olds in the multivariate analysis of risk factors, unlike the univariate analysis. SAC versus non-SAC ( $\mathrm{p}=$ 0.027 ) and depth (SI or SE vs. SS, p = 0.001) were independent prognostic factors (table 4).

\section{Discussion}

The incidence of right-sided colon cancer is increasing in older Japanese patients, especially females [3, 4]. This tendency probably can be attributed to the effect of lifestyle changes related to westernization in Japan [20, 21]. Laterally spreading tumor and sessile serrated ade- 
Table 4. Stepwise multivariate survival analysis using Cox's proportional hazards model

\begin{tabular}{llll}
\hline Risk factor & SE & p value & Hazard ratio (95\% CI) \\
\hline Age $(\geq 70$ vs. $<70)$ & 0.54481 & 0.066 & $2.71930(0.93479-7.91042)$ \\
Depth of tumor (SI or SE vs. SS) & 0.61338 & 0.001 & $7.30061(2.19407-24.2923)$ \\
SAC vs. non-SAC & 0.55868 & 0.027 & $3.43885(1.15044-10.2793)$ \\
\hline
\end{tabular}

noma/polyp (SSA/P) are thought to be important manifestations of interval cancer in the rising right side of the colon because these lesions are flat $[6,7,22,23]$. SSA/P has been classified as a subtype of hyperplastic polyp in the nondysplastic category, but both genetic background and proliferation differed between SSA/P and hyperplastic polyp. It is currently noted that SSA/P is a feature of the new serrated neoplasia pathway. The pathway of the SSA/P-MSI-H carcinoma sequence was reported by Snover et al. [10]. SSA/P might arise directly from normal mucosa or develop from a preexisting microvesicular hyperplastic polyp, although this remains debatable. Mutation of BRAF and methylation of the $\mathrm{CpG}$ island promoter regions are common in these lesions [10]. It is worth noting that the serrated neoplasia pathway differs from the conventional Vogelstein adenoma-carcinoma sequence [8] and SAC is a particular subtype of colorectal carcinoma that arises from oncogenic transformation in SSA/P of the right side of the colon.

On this basis, we analyzed the relationship between SAC and prognosis. We collected subjects with Dukes' B colorectal cancer for this study. From the clinical outcome we knew that the prognosis might be good in Dukes' A, poor in Dukes' C and diverse in Dukes' B. Statistical significance in survival analysis was obtained from SAC cases and non-SAC cases matched for Dukes' B. GarcíaSolano et al. [13] reported similar results to us but they did not assess their cases according to Dukes' stage. Leftsided SACs had the worst clinical outcome in the report of García-Solano et al. [13] but we did not find significant differences in mortality based on the location of the tumor. The reason for this result might be that we collected only Dukes' B cases for our study.

Molecular changes have been analyzed in various studies. Tuppurainen et al. [16] reported in 2005 that SAC was not directly related to microsatellite instability and Laiho et al. [24] identified in 2007 the ephrin receptor B2, hypoxia-inducible factor 1-alpha and patched (PTCH1) as proteins important for the genesis of SAC. Stefanius et al. $[25,26]$ did not report any deleterious inactivating PTCH1 mutation in SAC but, in 2011, they observed that SAC is characterized by BRAF and KRAS mutations and it is conceivable that the loss of the PTCH1 protein expression may result from constant activation of the mitogen-activated protein kinase pathway, caused by either KRAS or BRAF mutations.

The molecular mechanisms involved in SAC are not clearly understood. There are various problems including that the histologic evaluation of SAC is not standardized and the question of which sequence or gene is associated with SSA/P developing into SAC has not been addressed sufficiently. It is clear from our study that SAC is a subtype of colorectal carcinoma with unique histologic features and a poorer prognosis. Accordingly, SAC is considered an independent predictor of prognosis with depth. This is the first study in Japan to investigate the correlation between the prognosis and SAC defined by Mäkinen [17] in Dukes' B.

\section{Acknowledgments}

This work was supported by the Japanese Society for Cancer of the Colon and Rectum, a Dokkyo Medical University Young Investigator Award to Y.S. (No. 2011-03-5) and a Grant in Aid for Scientific Research to T.F. (C).

The authors greatly thank C. Matsuyama, A. Shimizu, T. Ono, M. Katayama, N. Nagashima, S. Kidate and A. Kikuchi (Department of Surgical and Molecular Pathology, Dokkyo University School of Medicine) for their excellent technical and secretarial assistance.

\section{Disclosure Statement}

The authors declare that no financial or other conflicts of interest exist in relation to the contents of the article. 


\section{References}

$>1$ Shin HR, Masuyer E, Ferlay J, Curado MP: Cancer in Asia - incidence rates based on data in cancer incidence in five continents IX (1998-2002). Asian Pac J Cancer Prev 2010; 11:11-16.

-2 Okamoto M, Shiratori Y, Yamaji Y, Kato J, Ikenoue T, Togo G, Yoshida H, Kawabe T, Omata M: Relationship between age and site of colorectal cancer based on colonoscopy findings. Gastrointest Endosc 2002;55:548551.

>3 Yamaji Y, Mitsushima T, Ikuma H, Watabe $\mathrm{H}$, Okamoto M, Yoshida H, Kawabe T, Wada R, Omata M: Right-side shift of colorectal adenomas with aging. Gastrointest Endosc 2006;63:453-458.

-4 Yamaji Y, Mitsushima T, Yoshida H, Watabe H, Okamoto M, Ikuma H, Wada R, Kawabe T, Omata M: Right-side shift of metachronous colorectal adenomas after polypectomy. Scand J Gastroenterol 2007;42:14661472.

5 Sugihara K, Kusunoki M, Watanabe T, Sakai Y, Sekimoto M, Ajioka Y: Guidelines for classification; in Japanese Society for Cancer of the Colon and Rectum (ed): Japanese Classification of Colorectal Carcinoma. Tokyo, Kanehara, 2009, pp 1-34.

-6 Arain MA, Sawhney M, Sheikh S, Anway R, Thyagarajan B, Bond JH, Shaukat A: CIMP status of interval colon cancers: another piece to the puzzle. Am J Gastroenterol 2010; 105:1189-1195.

7 Sawhney MS, Farrar WD, Gudiseva S, Nelson DB, Lederle FA, Rector TS, Bond JH: Microsatellite instability in interval colon cancers. Gastroenterology 2006;131:1700-1705.

$>8$ Vogelstein B, Fearon ER, Hamilton SR, Kern SE, Preisinger AC, Leppert M, Nakamura Y, White R, Smits AM, Bos JL: Genetic alterations during colorectal-tumor development. N Engl J Med 1988;319:525-532.

9 Hamilton SR, Bosman FT, Boffetta P, Ilyas M, Morreau H, Nakamura SI, Quirke P, Riboli E, Sobin LH: Carcinoma of the colon and rectum; in Bosman FT, Carneiro F, Hruban RH, Theise ND (ed): WHO Classification of Tumours of the Digestive System. Lyon, International Agency for Research on Cancer, 2010, pp 134-146.
10 Snover DC: Update on the serrated pathway to colorectal carcinoma. Hum Pathol 2011; 42:1-10.

11 Snover DC, Ahnen DJ, Burt RW, Odze RD: Serrated polyps of the colon and rectum and serrated polyposis; in Bosman FT, Carneiro F, Hruban RH, Theise ND (eds): WHO Classification of Tumours of the Digestive System. Lyon, International Agency for Research on Cancer, 2010, pp 160-165.

12 O'Brien MJ, Yang S, Mack C, Xu H, Huang CS, Mulcahy E, Amorosino M, Farraye FA: Comparison of microsatellite instability, CpG island methylation phenotype, BRAF and KRAS status in serrated polyps and traditional adenomas indicates separate pathways to distinct colorectal carcinoma end points. Am J Surg Pathol 2006;30:1491-1501.

13 García-Solano J, Pérez-Guillermo M, Conesa-Zamora P, Acosta-Ortega J, Trujillo-Santos J, Cerezuela-Fuentes P, Mäkinen MJ: Clinicopathologic study of 85 colorectal serrated adenocarcinomas: further insights into the full recognition of a new subset of colorectal carcinoma. Hum Pathol 2010;41: 1359-1368.

14 Yao T, Nishiyama K, Oya M, Kouzuki T, Kajiwara M, Tsuneyoshi M: Multiple 'serrated adenocarcinomas' of the colon with a cell lineage common to metaplastic polyp and serrated adenoma: case report of a new subtype of colonic adenocarcinoma with gastric differentiation. J Pathol 2000;190:444-449.

15 Jass JR, Smith M: Sialic acid and epithelial differentiation in colorectal polyps and cancer - a morphological, mucin and lectin histochemical study. Pathology 1992;24:233242.

16 Tuppurainen K, Mäkinen JM, Junttila O, Liakka A, Kyllönen AP, Tuominen H, Karttunen TJ, Mäkinen MJ: Morphology and microsatellite instability in sporadic serrated and non-serrated colorectal cancer. J Pathol 2005;207:285-294.

17 Mäkinen MJ: Colorectal serrated adenocarcinoma. Histopathology 2007;50:131-150.

18 Sobin LH, Brierley J: Digestive system tumours. Colon and Rectum; in Sobin LH, Gospodarowicz MK, Wittekind Ch (eds): TNM Classification of Malignant Tumours. Chichester, Wiley-Blackwell, 2010, pp 100105.
19 Imura J, Ichikawa K, Takeda J, Fujimori T: Beta-catenin expression as a prognostic indicator in cervical adenocarcinoma. Int J Mol Med 2001;8:353-358.

20 Kotake K, Honjo S, Sugihara K, Kato T, Kodaira S, Takahashi T, Yasutomi M, Muto T, Koyama Y: Changes in colorectal cancer during a 20-year period: an extended report from the multi-institutional registry of large bowel cancer, Japan. Dis Colon Rectum 2003;46:S32-S43.

21 Yiu HY, Whittemore AS, Shibata A: Increasing colorectal cancer incidence rates in Japan. Int J Cancer 2004;109:777-781.

22 Sugimoto T, Ohta M, Ikenoue T, Yamada A, Tada M, Fujishiro M, Ogura K, Yamaji Y, Okamoto M, Kanai F, Kawabe T, Omata M: Macroscopic morphologic subtypes of laterally spreading colorectal tumors showing distinct molecular alterations. Int J Cancer 2010;127:1562-1569.

23 Fujita K, Yamamoto H, Matsumoto T, Hirahashi M, Gushima M, Kishimoto J, Nishiyama K, Taguchi T, Yao T, Oda Y: Sessile serrated adenoma with early neoplastic progression: a clinicopathologic and molecular study. Am J Surg Pathol 2011;35:295-304.

24 Laiho P, Kokko A, Vanharanta S, Salovaara $\mathrm{R}$, Sammalkorpi H, Järvinen $H$, Mecklin JP, Karttunen TJ, Tuppurainen K, Davalos V, Schwartz S Jr, Arango D, Mäkinen MJ, Aaltonen LA: Serrated carcinomas form a subclass of colorectal cancer with distinct molecular basis. Oncogene 2007;26:312-320.

25 Stefanius K, Kantola T, Tuomisto A, Vahteristo P, Karttunen TJ, Aaltonen LA, Mäkinen MJ, Karhu A: Downregulation of the hedgehog receptor PTCH1 in colorectal serrated adenocarcinomas is not caused by PTCH1 mutations. Virchows Arch 2011;458:213219.

26 Stefanius K, Ylitalo L, Tuomisto A, Kuivila R, Kantola T, Sirniö P, Karttunen TJ, Mäkinen MJ: Frequent mutations of KRAS in addition to BRAF in colorectal serrated adenocarcinoma. Histopathology 2011;58:679692. 